Fecha de recepción: mayo 2021 Fecha de aceptación: junio 2021 Versión final: julio 2021

\section{Analógicos, digitales y virtuales. Aproximaciones al recorrido evolutivo de la enseñanza del Diseño Industrial.}

\author{
Alan Neumarkt ${ }^{(1)}$
}

Resumen: Un recorrido histórico lineal sobre la enseñanza del Diseño Industrial, con algunas asociaciones vinculadas a la filosofía y al contexto. Una reflexión sobre tres momentos de la praxis en la enseñanza, iniciada a través de herramientas analógicas, posteriormente el salto veloz a la digitalización y a la emergencia de la virtualidad, hecho que podría marcar un cambio de época.

Palabras clave: Diseño - Industria - Tecnología - Diseño digital - Enseñanza virtual.

[Resúmenes en inglés y portugués en la página 36]

(1) Diseñador Industrial FBA UNLP. Doctor en Diseño FADU UBA. Profesor Titular Regular FAUD UNMdP. Profesor Posgrado UBA y UNTreF. Director de Educación Superior ORT, Argentina.

"El Diseño es un complicado acto de fe".

(John Christopher Jones)

El Diseño Industrial es un territorio fascinante en tanto se puede abordar desde su plano visual y operacional (Form follows function se discutirá desde Sullivan); se puede abordar en su gramática, de la idea al partido y a través de leyes subyacentes (Maldonado, Ricard, Bonsiepe); y en otros casos se puede analizar desde la geometría (Breyer, Doberti) o también desde la tecnología de producción (Ortega, Mumford)

Avanzando a niveles de profundidad, podría haber un abordaje desde su semántica (Jung, Barthes, Krippendorff) o desde la filosofía (Marcuse, Pierce, Simondon, Sennett).

Las universidades enseñan desde lo visual y su gramática. La semántica y la filosofía requieren horas de vuelo; muy poco se hace en los posgrados y hay un territorio aún muy inexplorado. Las Artes Plásticas vienen haciendo más que el Diseño en este campo. 
La Filosofía de la Tecnología es un tema de gran importancia. La enseñanza de grado, los planes de estudios universitarios, casi nunca consideran a la filosofía en su contenido académico. Deberían hacerlo. El Diseño Industrial no debe escaparse de su definición. La Tecnología con su brazo ejecutor, la Industria, es uno de sus pilares. Lo lleva en su nombre. En El hombre unidimensional, Herbert Marcuse plantea la oscilación del hombre entre dos hipótesis contradictorias, a saber: a) la sociedad industrial avanzada es capaz de contener la posibilidad de un cambio cualitativo y $b$ ) existen fuerzas y tendencias que pueden romper esta contención y hacer estallar a la sociedad. Establece la no-neutralidad tecnológica y conforme el proyecto histórico-social se desarrolla, configura el universo del discurso y la acción de la cultura intelectual y material.

Se pregunta Marcuse sobre el hecho brutal del poder físico que sobrepasa al individuo o grupo y hace de la máquina el instrumento más efectivo de la sociedad. Me pregunto si es solamente poder físico, entendiendo que hoy podría leerse también un poder psicológico, sobre deseos, necesidades y hasta adicciones del sujeto con el objeto.

La idea de llamar a las cosas como máquinas se encuentra ya en el Siglo XVIII (Le Mettrie) y se ve mucho en la literatura técnica de la Segunda Guerra Mundial; el concepto hombremáquina da nacimiento a la Ergonomía. Martin Heidegger en Arte y Poesía menciona lo cósico de la materia. Para ser más amplio en la descripción de esta relación prefiero hablar de sujeto-objeto o en términos solamente industriales de sujeto-producto.

$\mathrm{Si}$, como plantea Marcuse, las necesidades humanas han sido preconcebidas, el Diseño Industrial tiene en su haber -asumido o no, esa es otra cuestión- ser la herramienta que lo permite. "La gente se reconoce en sus mercancías, encuentra el alma en su automóvil".

Esta lectura le daría entonces cierta grandeza al Diseño Industrial, pero sería una lectura desde dentro de la profesión misma. No parece suficiente porque tal vez podría haber un dilema de origen.

El texto de Marcuse es de 1954. Casi al mismo tiempo, a metros de allí, la Escuela de Proyectación de la ciudad de Ulm -HfG Ulm, con Aicher, Bill y Maldonado a la cabezasentaba las bases de la profesión, que al día de hoy sigue siendo la base epistemológica de la enseñanza del Diseño Industrial.

Entonces, podría haber un conflicto de origen en la asociación del Diseño con lo Industrial. Diseño en tanto proyecto, es idea de futuro, de creación, de libertad e innovación, de resolución de problemas siempre en búsqueda de calidad. Calidad de producto y calidad de vida como consecuencia.

La industria y su origen, que podría remontarse a tiempos remotos, pero podemos convenir que hay un punto notable desde Newcomen y Watt, basa su razón de ser en la eficiencia, en su ideología para la maximización de recursos materiales, humanos y económicos. En la seriación y su evolución Fordiana. Crear riqueza y luego distribuirla. La racionalidad tecnológica transforma a la sociedad y la domina. La mecánica contra la libertad, nuevamente Marcuse.

La tensión Diseño-Industria podría ser el dilema del Diseño Industrial como profesión. Ricardo Blanco en Crónicas del diseño industrial en Argentina habla del Diseño a pesar de la Industria. Yo prefiero mantener mi postura de que hay Diseño Industrial porque hay Industria. El pragmatismo como idea filosófica podría dar algunas respuestas. 
El Diseño disciplinar ya estaba instalado desde Gropius en Bauhaus. La llegada del nazismo al poder en Europa provocó el cierre definitivo de la Bauhaus y la emigración de buena parte de sus profesores notables. Tuvo que esperarse hasta la segunda posguerra para que en Alemania se creara otra institución, que fuera heredera del legado proyectual y académico de la primera: la mencionada HfG Ulm. Ya desde 1946, Inge Scholl y Otl Aicher desarrollaron el proyecto. Finalmente la escuela fue creada en 1953 por donaciones de Inge y Grete Scholl -en memoria de dos de sus hermanos ejecutados por el régimen nazi por sus actividades en la resistencia- y con el objetivo de vincular la enseñanza e investigación con la reconstrucción de la sociedad.

En abril de 1953 comenzó a funcionar la nueva institución universitaria con Max Bill, ex alumno de la Bauhaus, como rector y con un cuerpo docente integrado por Hans Gugelot, Otl Aicher, Johanes Itten, Helene Nonné-Schimidt y Tomás Maldonado, arribado desde Buenos Aires tras sus acciones primero en el Arte Concreto y después con la revista Nueva Visión y la agencia de publicidad Axis. Los conflictos internos provocan la salida de Bill y el reemplazo por Tomás Maldonado. Comienza una etapa más sistemática, racional y una estrecha colaboración con la industria, sobre todo con la marca de electrodomésticos Braun. Otl Aicher, Hans Gugelot, y sus alumnos desarrollan nuevos diseños para que la empresa los fabricara. Surge la Gute Form, el concepto de Buena Forma. Los conflictos, disputas académicas y problemas de subvenciones y financiamiento se sucedieron en forma constante hasta el cierre definitivo de la HfG Ulm en 1968.

El lado estadounidense del diseño y de la industria marchaba por otro camino. La Segunda Guerra había diezmado tropas pero no había afectado al territorio y el triunfo le daba un marco al progreso que la tecnología industrial bélica había desarrollado. Un poco antes, en 1937 ya estaban sentadas las bases del Streamline, un estilo decó tardío de tendencias formales aerodinámicas que tuvo en el diseño industrial a Raymond Loewy como adalid. La locomotora para la Pennsylvania Rail Road es un ícono de época. Prefiguraba el futuro.

\section{Analógicos}

Los trabajos de Richard Sennett se inscriben en lo que él mismo llama cultura material. El movimiento del pragmatismo da una existencia filosófica a la experiencia concreta. Fue la reacción norteamericana al idealismo europeo de Hegel. Tras la segunda posguerra del Siglo XX, surgieron años de dualidad y contradicción, consecuencia de la Guerra Fría. En el ámbito local hay un diálogo bastante reciente en esos años de la sociedad argentina con el Diseño. La industria demuestra su crecimiento pero ésta a su vez pone en evidencia ciertos atrasos tecnológicos. Sin duda marca un cambio de época y una generación que fue de su recorrido militante hasta la transformación actual en la era digital.

Dentro de este contexto se instala la enseñanza del Diseño Industrial en Argentina. En 1963 se crearon las carreras de Diseño en la Universidad Nacional de La Plata y en la Universidad Nacional de Cuyo en Mendoza y recién hubo profesionales egresados a partir de 1968. 
Tanto en la enseñanza como el desarrollo profesional se dibujaba a mano, con rigor instrumental en la documentación técnica y con elementos artísticos en la expresividad. En tres dimensiones se modelaban maquetas físicamente, como una escultura, no en el sentido actual que la profesión da a la palabra modelar.

Y es entonces que aquel Taller proyectual se asemeja al taller del artesano, como enuncia Sennett (2009) en su libro:

El hecho más importante que conocemos acerca del taller de Stradivarius es la apasionada dedicación de su maestro, que saltaba inesperadamente de un sitio a otro, reuniendo y procesando los miles de pequeños fragmentos de información, que podían no tener el mismo significado para los asistentes que sólo se ocupaban de una parte del proceso. Lo mismo ocurre en los laboratorios científicos dirigidos por genios idiosincrásicos: la cabeza de su director o directora se llena de una información cuyo sentido sólo él o ella pueden captar. Por eso es imposible penetrar en los secretos del físico Enrico Fermi si sólo se estudian los detalles de sus procedimientos de laboratorio. Para expresar esta observación en lenguaje abstracto: en un taller en el que dominan la individualidad y la originalidad del maestro, es probable que también domine el conocimiento tácito.

Dentro de este pragmatismo, de un aprender haciendo, aparece en 1985 -como por arte de magia- un libro puramente operativo que se transforma en el paradigma del lenguaje profesional: Presentation Techniques, de Dick Powell. Se produce un antes y un después.

El rendering analógico se instala como estilo, el uso de marcadores y sus trucos de sombras y reflejos se masifica, y los estudiantes emulan y compiten por el atractivo visual. Algunos -muy talentosos- se destacan con estilo propio. En la FBA UNLP, Gustavo Fosco y Alejandro Ruiz se hacen notar. En la FADU UBA, recientemente creada, asombra Rafael Varela. La posterior trayectoria profesional de cada uno de ellos habla muy bien de la enseñanza universitaria de aquellos años.

\section{Digitales}

Nicolás Negroponte, analista y escritor, fundador del MIT Media Lab, publicó su famoso libro Ser digital en 1995. En esencia estableció la transformación del mundo de los átomos a los bits.

Diez años antes en una excursión nocturna y algo clandestina Marcelo Leslabay y quien escribe, tuvimos una primera aproximación. Gracias al contacto de un programador de computadoras, nos introdujimos en un importante edificio de oficinas del centro de Buenos Aires en ese horario tardío de limpieza y mantenimiento. Él tenía las llaves por ser encargado de dar soporte técnico a los servidores y fue así que esa noche nos mostró en una sala especialmente acondicionada la imponente Intergraph (ver Figura 1). Una estación de trabajo de dos monitores en paralelo y un gran tablero de comandos. Nada que hoy pueda 
sorprendernos mucho pero que, para 1985, era lo más avanzado que había en la ciudad en equipos para dibujo asistido por computadora.

Tres años después Juan Santana, un intrépido alumno de la primera promoción de Diseño Industrial de FADU UBA, presentaba sus trabajos en Autocad 8, con la mayor precisión de la época, donde un círculo podría casi confundirse con un octógono, pero que dada la novedad tecnológica hizo que la estética del dibujo digital pasara a ser arte y parte. Otros alumnos como Javier Izbicki y Victor Blebel pronto adoptaron las habilidades necesarias en un software del momento llamado Cimatrón y de a poco, tanto arquitectos como diseñadores, fueron incorporando el mouse junto al lápiz.

Por otro lado, las empresas de hardware descubrieron que los diseñadores debían ser los creadores de esos objetos que contenían tanta electrónica. Steve Jobs contrató a Hartmut Esslinger y Frog Design marcó el camino. De alguna manera los diseñadores estaban diseñando las máquinas donde diseñar.

La transición de analógicos a digitales no fue fácil ni instantánea y fundamentalmente sucedió en la década siguiente, cuando el costo de los equipos disminuyó considerablemente. El Diseño Gráfico lo adoptó con mucha rapidez en cambio, a las carreras proyectuales de tres dimensiones, les costó un poco más. Tanto por la capacidad de procesamiento, como por la calidad del resultado que necesitó de mucho tiempo de desarrollo.

Para mayo de 1989, a instancias de un convenio firmado por FADU UBA con el Politécnico de Lausanne en Suiza, el decano Borthagaray y los profesores Cristina Argumedo y Arturo Montagú ponen en marcha el Centro CAO, espacio de investigación y capacitación en este nuevo mundo digital, que había llegado para quedarse.

Así transcurrió la enseñanza del Diseño Industrial los siguientes 30 años. No perdió su base geométrica, si se quiere ulmiana, sí fue perdiendo en muchos casos la calidad del dibujo manual, mucho más personal, reemplazado por cada vez mejores y más veloces softwares. Se ganó en calidad en masa, pero se perdió identidad y sobre todo emoción.

\section{Virtuales}

Las aulas no son solamente alumnos y un docente. Por supuesto no son las paredes, menos el edificio. Hay algo más. Un contrato tácito dirán algunos, un vínculo psico-social podrían pensar otros; una comunión tal vez, esa unión en común por alcanzar algo nuevo. Marzo de 2020. El contexto cambió. El aula, el edificio, la calle, la ciudad, el mundo entero quedó atrapado en la pandemia de Covid-19; cuarentena temporaria o tal vez prefacio de un cambio de época. Podría ser que se vuelva a la docencia presencial en la universidad en algún momento. Pero también muchas cosas distintas podrían suceder. El tiempo que va transcurriendo va acumulando ya muchas horas de educación virtual en Diseño. Y, recorriendo las universidades del país, el compromiso continúa. El aula, como concepto, en cualquier formato sigue existiendo. Aparecieron -pasaron al frente- plataformas, programas, videoconferencias y conectividades varias. La esencia no ha cambiado. Retornando a Jones: El Diseño sigue siendo un acto de fe. 


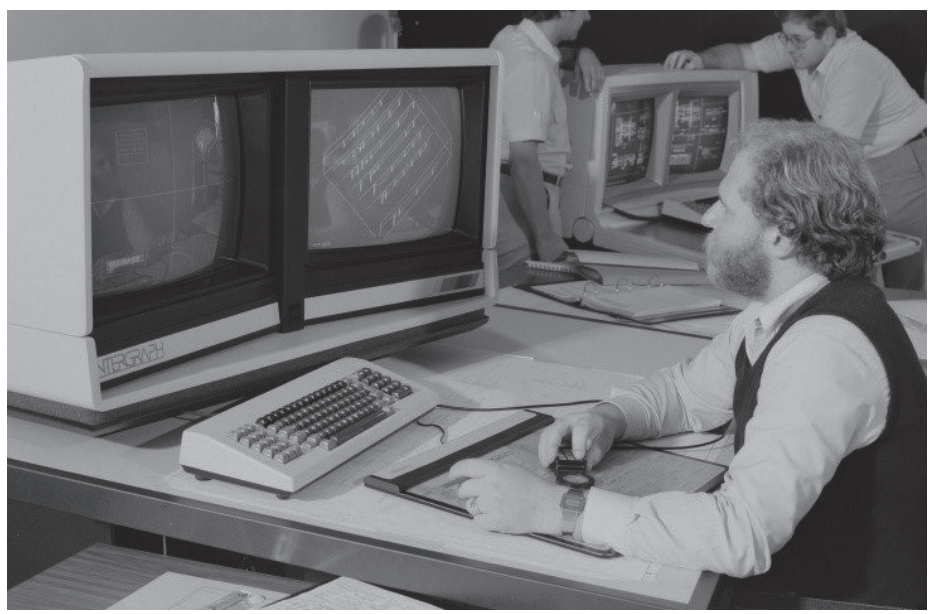

Figura 1: Worksation / Intergraph (1985).

Fuente: elaboración propia tomada del catálogo publicitario en papel.

\section{Listado de Referencia Bibliográfica}

Blanco, R. (2005). Crónicas del diseño industrial en Argentina. Buenos Aires: Ed. FADU. Devalle, V. (2009). La travesía de la forma. Buenos Aires: Ed. Paidós. Jones, J. C. (1966). Métodos de Diseño. Barcelona. Ed. Gustavo Gigli. Lucena, D. (2015). Contaminación artística. Buenos Aires: Ed. Biblos. Maldonado, T. (1977). El diseño industrial reconsiderado. Barcelona: Ed. Gustavo Gili. Marcuse, H. (1954). El hombre unidimensional. Boston, USA: Bacon Press.

Powell, D. (1985). Presentation Techniques. Orbis First: Reino Unido / Seix Barral / Planeta. Sennett, R. (2009). El artesano. Barcelona: Ed. Anagrama.

Abstract: A linear historical tour on the teaching of Industrial Design, with some associations linked to philosophy and context. A reflection on three moments of praxis in teaching, initiated through analog tools, later the rapid leap to digitization and the emergence of virtuality, a fact that could mark a change of era.

Keywords: Design - Industry - Technology - Digital design - Virtual teaching.

Resumo: Um percurso histórico linear sobre o ensino do Desenho Industrial, com algumas associações ligadas à filosofia e ao contexto. Uma reflexão sobre três momentos da 
práxis no ensino, iniciada por meio de ferramentas analógicas, depois o rápido salto para a digitalização e o surgimento da virtualidade, fato que pode marcar uma mudança de época.

Palavras chave: Design - Indústria - Tecnologia - Design digital - Ensino virtual.

[Las traducciones de los abstracts fueron supervisadas por el autor de cada artículo] 